not warrant the cost of an institute, it does call for a standing committee empowered to speak with authority for the profession. To implement formation of this central geological committee, it is suggested that a government departmental committee of inquiry be appointed to review and report on the present organisation of British and Colonial geology, to consider the position of existing institutions and make recommendations in relation to them. There has been a marked lag in development of British geological survey organisation during the past twenty years. Furthermore, there is a scarcity of entrants into the profession, due possibly to the break in training during the war years, but more probably to conditions of pay and service, which are not comparable with those offered by industry. The writer of the article believes that many present difficulties might be resolved by a speedy reorganisation of institutions in the United Kingdom to meet the needs 5 ff a joint British and Colonial survey.

\section{Education for Adjustment to Ageing}

IN the British Mes the proportion of persons sixty years of age ayd more will be about 20 per cent in 1979 as ags dust about 5 per cent in 1901. This ageing of the population creates serious problems for the indivi\&dal and for society, particularly when considfred in relation to the great reduction in manpower required to produce the goods and services needed in the country. After investigating some of these individual and social problems, a year ago the University of Michigan carried out an experimental twelve-weeks course on the adjustment to ageing; details of the course have been set out by Clark Tibbets, director of the Institute for Human Adjustment, University of Michigan, in the July issue of Health Education (7, No. 3; 1949). The course was based on the principles that growing old is a life-long process of development and atrophy and requires individual behaviour adjustment as each new stage is reached, and that successful living at any age requires preparation. All phases of life were covered in eight broad groups, and practical suggestions were given to aid in individual adjustment. The eight groups included biological ageing, psychological changes, maintenance of physical and mental health, living arrangements, creative activities, religion, social and economic security, and legal problems. Some interesting results were obtained on the courses. The first drew fifty people; the second had an enrolment of ninety. The students took a more objective attitude to ageing, giving more attention to their physical well-being and seeking ways to exercise their mental capacities as well as demanding opportunity forg flf-expression and social participation.

\section{Outline of the History of Mathematics}

A RECENT number of the American Mathematical Monthly (56, J0. 1, Pt. 2, pp. 114; University of Buffalo, N. 1 dollar), entitled "Outline of the Histor of Mathematics" by R. C. Archibald, contaifs a Very remarkable synopsis of the history of nathdmatics, beginning with the Babylonians and Eg $x$ tians, and proceeding to the Greeks, then to Hindu, Arabic and Persian mathematics, and thence to European mathematics to 1600 A.D. Following this are sections dealing with the seventeenth, eighteenth and nineteenth centuries and later. The literature list and notes and the index of names at the end are most helpful to anyone consulting the book.
Nest Recordsnof the Song-Thrush

UNDER its, nest record card scheme, members of the Britis cr rust for Ornithology are asked to com. plete pycard for every nest of every species that they finc, ging details of locality, situation, number of efg' 'and young and other particulars, together with the dates of recording. This method of inquiry represents a valuable advance in the technique of field ornithology, and, in a recent issue of British Birds, Miss E. T. Silva shows that much interesting material has been collected from 173 nest record cards for the song thrush (Turdus ericetorum) $(42$, No. 4 ; April 1949). The collated information shows that the usual laying period for the song-thrush in Britain is from mid-March to mid-July, when it generally lays a clutch of four or five eggs. The average clutch-size in Britain increases from early spring to a peak in May, and then decreases again. A similar seasonal variation occurs in Holland and Finland; but in the latter the peak occurs in June. The average clutch-size is larger in Holland than in Britain and larger still in Finland, at the same time of year. There is a significant variation in average brood-size in different years in Britain, and predation is the most usual cause of nesting failure. Nesting success does not vary appreciably with clutch-size or season. The song-thrush usually lays one egg each day until the clutch is complete; a few exceptions have been recorded, but more observations are needed. The average incubation period is 13.4 days and the nestling period is 13.2 days. Both periods appear to be slightly longer in the early part of the season.

National Museumper Victoria

THE annual eoport of the National Museum of
Victoria for $147-48$ states that representations made to the firofornment have resulted in the acquisition of a sfor in the King's Domain for a new museum building. It is intended to house the natural history afin ethnology in this new accommodation. The present Museum is so restricted both as regards the exhibition galleries and storage space that the prospect of a new building is especially welcome to museum staff and public alike. The director (Mr. R. T. M. Pescott) was granted seven months leave of absence to study design of museum buildings in Europe and the United States.

\section{Quicker Forcing of Seakale}

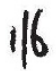

Pre-heating seakale crowns in water at $35^{\circ} \mathrm{C}$. for three hours is show $\mathrm{n}$ by I. F. Storey and N. Montgomery $(J$.$) fart. Sci., 24, Nos. 3$ and 4, 214 ; Dec. 1948) th git an increased yield of forced kale. Abgit on -third more was obtained with ordinary comn Arcial varieties, and larger increases with now early forcing types. Pre-heating could also be used to reduce the length of the forcing period.

\section{Man-power Statistics of the British Civil Selvice}

IN a written reply to a question in the House of Commons of November 29, the Financial Secretary to thenTresury stated that there were 411,762 establis non-industrial Civil servants on October 1 , 1949. as against 382,308 on January 1,1949 . An acchimpanying analysis by staff groups of the establishet and unestablished figures for October 1 shows that in the administrative class there were 2,689 established and 663 unestablished; 12,808 professional (scientific and technical I) established and 7,808 unestablished; 14,230 scientific and technical II established, and 21,426 unestablished; 19,566 